\title{
PEMBUATAN SABUN TRANSPARAN DENGAN PENAMBAHAN EKSTRAK BATANG PEPAYA SEBAGAI ANTIBAKTERI
}

\author{
Marita TM Simbolon, Yelmira Zalfiatri*, and Faizah Hamzah \\ Program Studi Teknologi Hasil Pertanian, Jurusan Teknologi Pertanian, \\ Fakultas Pertanian, Universitas Riau, Kode Pos 28293, Pekanbaru \\ e-mail: zalfiatri@gmail.com
}

Diterima: 09 Oktober 2018 / Disetujui: 07 Desember 2018 / Dipublikasi online: 15 Desember 2018 DOI: $10.22437 /$ chp.v3i2.5713

\begin{abstract}
This study aimed to obtain the amount of addition of papaya stem extract in inhibited the growth of Escherichia coli and Staphylococcus aureus in making of transparent soap. The study used complete randomized design consisted of 4 treatments and 4 replications. The treatments in this study were papaya stem $10 \mathrm{mg} / \mathrm{ml}(P 1)$, addition of papaya stem extract $15 \mathrm{mg} / \mathrm{ml}$ (P2), addition of papaya stem extract $20 \mathrm{mg} / \mathrm{ml}$ (P3), addition of papaya rod extract $25 \mathrm{mg} / \mathrm{ml}$ (P4). The parameters observed were moisture content, fatty acid level, free fatty acid/alkali free, $p H$, foam stability, antibacterial test and irritation test. The results showed that the addition of papaya stem extract had significant effect on water content, fatty acid content, free fatty acid, $p H$, foam stability, antibacterial test and irritation test. The selected treatment in this study was $P 3$ treatment (addition of papaya stem extract $20 \mathrm{mg} / \mathrm{ml}$ ) with water content $13.24 \%$, total fatty acid 27.00, free fatty acid 1.73\%, pH, 11.06, foam stability 90.99\%, antibacterial activity against S.aureus $8.57 \mathrm{~mm}$ and to E.coli $10.33 \mathrm{~mm}$, erythema irritation 0.05 (almost invisible).
\end{abstract}

Keywords: Transparent soap, papaya stem, antibacterial

\section{ABSTRAK}

Penelitian ini bertujuan untuk mendapatkan jumlah penambahan ekstrak batang pepaya dalam menghambat pertumbuhan Escherichia coli dan Staphylococcus aureus dalam pembuatan sabun transparan. Penelitian menggunakan rancangan acak lengkap yang terdiri dari 4 perlakuan dan 4 ulangan. Perlakuan dalam penelitian ini adalah batang pepaya $10 \mathrm{ml}$ $(P 1)$, penambahan ekstrak batang pepaya $15 \mathrm{ml}(P 2)$, penambahan ekstrak batang pepaya $20 \mathrm{ml}$ (P3), penambahan ekstrak batang pepaya $25 \mathrm{ml}$ (P4). Parameter yang diamati adalah kadar air, kadar asam lemak, asam lemak bebas / alkali bebas, pH, stabilitas busa, uji antibakteri dan uji iritasi. Hasil penelitian menunjukkan bahwa penambahan ekstrak batang pepaya berpengaruh nyata terhadap kadar air, kadar asam lemak, asam lemak bebas, $p H$, stabilitas busa, uji antibakteri dan uji iritasi. Perlakuan yang dipilih dalam penelitian ini adalah perlakuan P3 (penambahan ekstrak batang pepaya $20 \mathrm{mg} / \mathrm{ml}$ ) dengan kadar air 13,24\%, asam lemak total 27,00, asam lemak bebas 1,73\%, pH, 11,06, stabilitas busa 90,99\%, aktivitas antibakteri terhadap S. aureus $8.57 \mathrm{~mm}$ dan E.coli $10.33 \mathrm{~mm}$, iritasi erythema 0.05 (hampir tidak terlihat).

Kata Kunci: Sabun transparan, batang pepaya, antibakteri

\section{PENDAHULUAN}

Pepaya merupakan tanaman yang cukup banyak dibudidayakan di Indonesia termasuk Riau. Selain bernilai ekonomi tinggi, tanaman pepaya juga mencukupi kebutuhan gizi. Sebagai buah segar pepaya banyak dikonsumsi, selain mengandung nutrisi yang baik, harganya juga relatif terjangkau dibandingkan dengan buah lainnya. Selain buah, bagian tanaman pepaya yang tidak kalah untuk dimanfaatkan yaitu batang 
pepaya. Batang pepaya merupakan salah satu bagian tanaman pepaya yang dapat dimanfaatkan sebagai antibakteri.

Antibakteri merupakan zat yang dapat menghambat dan membunuh pertumbuhan bakteri yang bertujuan untuk mencegah terjadinya infeksi. Infeksi merupakan penyakit yang diakibatkan oleh mikroorganisme patogen. Penelitian yang telah dilakukan oleh Oladimeji et al. (2007), bahwa ekstrak batang pepaya pada konsentrasi $1,5 \%$ dan $3 \%$ memiliki aktivitas antibakteri secara in vitro terhadap bakteri Escherichia coli dan Staphylococcus aureus. Nilai zona hambat secara radikal dan irradikal terhadap bakteri Escherichia coli sebesar $11.5 \mathrm{~mm}$ dan $12.0 \mathrm{~mm}$, sedangkan bakteri Staphylococcus aureus sebesar $14.0 \mathrm{~mm}$ dan $15.0 \mathrm{~mm}$. Batang pepaya mengandung senyawa metabolit sekunder golongan saponin, antrakuonin, alkaloid, tanin, dan flavonoid. Getah pada batang pepaya mengandung asam amino dan alkaloid, biasa digunakan sebagai obat demam, keracunan, bengkak, dan kurap. Menurut Oladimeji et al. (2007), dengan adanya golongan saponin dan golongan antrakuonin maka ekstrak batang pepaya berpotensi untuk digunakan sebagai antibakteri..

Penelitian yang dilakukan oleh Setiawan (2009) tentang aktivitas antibakteri ekstrak batang pepaya terhadap Staphylococcus aureus dan Escherichia coli, dapat diketahui bahwa terkandung golongan saponin dan antrakuonin. Saponin adalah suatu glikosida alamiah yang terikat dengan steroid atau triterpenoid. Antrakuinon merupakan suatu glikosida yang di dalam tumbuhan biasanya terdapat sebagai turunan antrakuinon terhidroksilasi, termitilasi, atau terkarboksilasi. Hasil uji aktivitas antibakteri menunjukkan bahwa ekstrak memiliki aktivitas antibakteri yang mampu menghambat dan membunuh bakteri, sehingga berpotensi untuk ditambahkan pada satu sediaan yang sering digunakan yaitu sabun.

Pemanfaatan antibakteri lain berupa minyak jeringau dalam pembuatan sabun antibakteri oleh Nadi (2017) dapat menghambat pertumbuhan bakteri Escherichia coli dan Salmonella typhi. Penelitian yang telah dilakukan oleh Rahman et al. (2011) yang menyatakan bahwa ekstrak batang pepaya pada konsentrasi $10 \mathrm{mg} / \mathrm{ml}$ memiliki aktivitas antibakteri terhadap Escherichia coli dan Salmonella typhi. Aktivitas antibakteri terhadap Escherichia coli menghasilkan diameter zona hambat sebesar $12 \mathrm{~mm}$ dan Salmonella typhi dengan diameter zona hambat sebesar $14.0 \mathrm{~mm}$. Selama ini pemanfaatan ekstrak batang pepaya digunakan pada pembuatan pasta gigi (Wulandari, 2013). Berdasarkan perlakuan yang dibuat oleh penulis terdahulu yang mana konsentrasi ekstrak batang pepaya yaitu $10 \mathrm{mg} / \mathrm{ml} ; 15 \mathrm{mg} / \mathrm{ml}, 20 \mathrm{mg} / \mathrm{ml}$, dan $25 \mathrm{mg} / \mathrm{ml}$ tetapi tidak diiringi dengan hasil produk, untuk itu penulis membuat perlakuan yang sama untuk ditujukan ke produk sabun transparan sekaligus untuk uji iritasi kulit. Berdasarkan uraian tersebut, penulis telah melaksanakan penelitian dengan judul Pembuatan Sabun Transparan dengan Penambahan Ekstrak Batang Pepaya (Carica papaya L.) dan Antibakteri. 


\section{METODOLOGI PENELITIAN}

\section{Alat dan Bahan}

Bahan utama yang digunakan pada penelitian ini adalah batang pepaya yang diperoleh dari kebun milik masyarakat di Jalan Bangau Sakti Kecamatan Tampan. Bahan lain yang digunakanan adalah akuades,minyak goreng, asam stearat, gliserin, etanol 96\%, sukrosa, dietanoamida, $\mathrm{NaCl} 1 \mathrm{~N}$, nutrient agar (NA), nutrien broth (NB), indikator phenolphthalein, indikator metil jingga, $\mathrm{NaOH} 30 \%, \mathrm{NaCl} 0.1 \mathrm{~N}, \mathrm{H}_{2} \mathrm{SO}_{4} 20 \%, \mathrm{KOH} 0.1 \mathrm{~N}$, heksana, $\mathrm{HCl} 0.1 \mathrm{~N}$, kertas lakmus kertas cakram ukuran $6 \mathrm{~mm}$, alumunium foil, bakteri uji Staphylococcus aureus ATCC-25329, dan Escherichia coli 0157 yang diperoleh dari Laboratorium Mikrobiologi Fakultas Kedokteran Universitas Riau Pekanbaru.

Alat yang digunakan dalam penelitian ini adalah pisau, baskom, talenan, kain saring, timbangan analitik, sentrifius, cetakan sabun, autoklaf, cawan porselen, desikator, penjepit cawan, oven, laminar air flow, inkubator, gelas piala, erlenmeyer, pH meter, inkubator, jangka sorong, pipet volume, pump pipet, lampu bunsen, penangas air, peralatan titrasi, spatula, hot plate stirrer, dan magnetic stirrer.

\section{Metode Penelitian}

Penelitian dilaksanakan dengan menggunakan metode Rancangan Acak Lengkap (RAL) yang terdiri dari empat (4) perlakuan dan empat (4) kali ulangan sehingga diperoleh enam belas (16) unit percobaan yaitu P1: Penambahan ekstrak batang pepaya $10 \mathrm{ml}$ P2: Penambahan ekstrak batang pepaya $15 \mathrm{ml}$ P3: Penambahan ekstrak batang pepaya $20 \mathrm{ml}$ P4: Penambahan ekstrak batang pepaya $25 \mathrm{ml}$. Penelitian ini menggunakan ampisilin sebagai kontrol positif dan penambahan ekstrak batang pepaya $0 \mathrm{ml}$ sebagai kontrol negatif.

\section{Ekstraksi Batang Pepaya}

Sortasi batang pepaya dilakukan pada saat setelah berbuah dengan umur yaitu 1 (satu) tahun 3 (tiga) bulan. Pepaya ditebang dan dipotong menjadi beberapa bagian. Dibersihkan dengan air mengalir. Dipotong dengan ukuran 2-5 $\mathrm{cm}$ dan dikeringkan dibawah sinar matahari, ditutupi menggunakan kain hitam, dihaluskan menggunakan mesin penggiling hingga menghasilkan serbuk, selanjutnya serbuk di ekstraksi dengan metode maserasi. Metode ekstraksi mengacu pada Wulandari (2013). Serbuk batang pepaya sebanyak 3000 g dimasukkan dalam toples kaca dan ditambahkan etanol 95\% hingga terendam selama 3 hari tanpa diganti pelarutnya sambil diaduk. Maserat yang telah didapat disaring dengan menggunakan kain flanel. Filtrat yang didapat dipisahkan menggunakan rotary evaporator. Setelah itu dipekatkan dengan menggunakan waterbath sampai didapatkan ekstrak kental, eksrak ditimbang dan disimpan dalam lemari pendingin.

\section{Pembuatan Sabun Transparan}

Pembuatan sabun transparan pada penelitian ini mengacu pada formulasi terbaik dari penelitian Nadi. (2017) dengan penambahan ekstrak batang pepaya. Asam stearat 
ditimbang sebanyak $7 \mathrm{~g}$, dilebur dalam $20 \mathrm{ml}$ minyak goreng curah pada suhu $70-80^{\circ} \mathrm{C}$. Sebanyak $20.3 \mathrm{ml}$ larutan $\mathrm{NaOH} 30 \%$ ditambahkan dan diaduk selama 5 menit hingga terbentuk stok sabun. Setelah terbentuk stok sabun, sebanyak $13 \mathrm{ml}$ gliserin, $15 \mathrm{ml}$ etanol, $17 \mathrm{ml}$ sukrosa, $1 \mathrm{ml}$ dietanolamida, dan $0.2 \mathrm{~g} \mathrm{NaCl}$ ditambahkan dan diaduk selama 10 menit pada suhu $50-60^{\circ} \mathrm{C}$ sampai homogen. Setelah itu ekstrak batang pepaya $(10,15,20$, dan $25 \mathrm{ml})$ air ditambahkan, kemudian diaduk pada suhu $40^{\circ} \mathrm{C}$ hingga homogen, lalu dituang kedalam cetakan dan didiamkan kurang lebih 24 jam pada suhu kamar

\section{Pembuatan Media}

Media Nutrient Broth (NB) untuk Perbanyakan Bakteri. Media yang digunakan untuk perbanyakan bakteri adalah Nutrient Broth yang dibuat dengan menimbang 0,2 g Nutrient Broth (NB) dan dilarutkan dengan akuades hingga volume $50 \mathrm{ml}$ didalam erlenmeyer. Larutan didistribusikan ke dalam tabung reaksi masing-masing sebanyak $5 \mathrm{ml}$, lalu ditutup dengan kapas dan dilapisi dengan aluminium foil. Kemudian disterilkan menggunakan autoklaf selama 15 menit pada suhu $121^{\circ} \mathrm{C}$. Medium ini digunakan untuk perbanyakan bakteri.

\section{Media Nutrient Agar untuk Pengujian Antibakteri}

Medium Nutrient Agar ditimbang sebanyak $10 \mathrm{~g}$, dimasukkan ke dalam erlenmeyer dan dilarutkan dengan akuades hingga volume $500 \mathrm{ml}$ dan diaduk. Medium ditutup dengan plastik dan aluminium foil serta diaduk dengan menggunakan magnetic stirrer sampai tercampur secara merata. Setelah itu, dilakukan sterilisasi dengan autoklaf pada suhu $121^{\circ} \mathrm{C}$ selama 15 menit. Medium diturunkan suhunya sampai sekitar $50-60^{\circ} \mathrm{C}$ dengan menempelkan thermometer pada dinding erlenmeyer. Larutan Nutrient Agar yang sudah steril kemudian didistribusikan ke dalam cawan petri dengan masing-masing bagian $15 \mathrm{ml}$. Penuangan medium dilakukan di dalam laminar air flow. Kemudian cawan petri yang berisi medium Nutrient Agar ditutup dan dibiarkan sampai membeku.

\section{Perbanyakan Bakteri}

Prosedur perbanyakan bakteri Staphylococcus aureus dan Escherichia coli mengacu pada Simanjuntak (2015). Isolat Staphylococcus aureus dan Escherichia coli masingmasing diinokulasikan sebanyak satu ose ke dalam tabung reaksi yang berisi media Nutrient Broth $5 \mathrm{ml}$. Kemudian diinkubasi pada suhu $37^{\circ} \mathrm{C}$ selama 24 jam dalam inkubator sehingga diperoleh kultur aktif dan berubah warna menjadi keruh. Kultur aktif disimpan dan siap digunakan.

\section{Aktivitas Antibakteri}

Uji aktivitas antibakteri sabun transparan dilakukan untuk mengetahui konsentrasi ekstrak batang pepaya yang mampu menghambat pertumbuhan mikroba patogen (Escherichia coli dan Staphylococcus aureus). Pengujian ini menggunakan metode difusi kertas cakram (Simanjuntak, 2015). Kertas cakram (diameter $6 \mathrm{~mm}$ ) direndam ke dalam larutan uji dengan konsentrasi 20\% (4 g sabun disuspensikan dalam $20 \mathrm{ml}$ air) dan 
diletakkan diatas permukaan media Nutrient Agar (NA) yang sebelumnya telah disebar 0,1 ml kultur mikroorganisme uji, kemudian diinkubasi pada suhu $37^{\circ} \mathrm{C}$ selama 24 jam. Diameter daerah hambat di sekitar kertas cakram diukur dengan menggunakan jangka sorong.

\section{Pengamatan}

Pengamatan yang dilakukan dalam penelitian ini adalah kadar air, asam lemak bebas/alkali beas mengacu pada Sudarmadji dkk. (1997), jumlah asam lemak mengacu pada Qisti (2009), pH mengacu pada Widayanti (2009), stabilitas busa mengacu pada Handayani (2009), aktivitas antibakteri mengacu Simanjuntak (2015), uji iritasi mengacu pada Trifena (2012), dan penilaian sensori yang mengacu pada Setyaningsih dkk.(2010).

\section{Analisis Data}

Data yang diperoleh dari pengukuran kadar air, kadar asam lemak, kadar asam lemak bebas/alkali bebas, stabilitas busa, uji kativitas antibakteri, uji iritasi dianalisis secara statistik dengan menggunakan ANOVA (analysis of variance). Jika Fhitung $\geq$ Ftabel maka analisis akan dilanjutkan dengan uji lanjut Duncan New Multiple Range Test (DNMRT) pada taraf $5 \%$.

\section{PEMBAHASAN}

Hasil sidik ragam terhadap kadar air, jumlah asam lemak, asam lemak bebas/alkali bebas, derajat keasaman $(\mathrm{pH})$, stabilitas busa, aktivitas antibakteri, uji iritasi. Hasil uji lanjut untuk setiap perlakuan pada berbagai pengamatan, dapat dilihat pada Tabel 1.

\section{Kadar Air}

Tabel 1 menunjukkan bahwakadar air sabun transparan berkisar antara 12.19$13.60 \%$. Semakin banyak penambahan ekstrak batang pepaya maka kadar air sabun padat transparan semakin rendah. Hal ini disebabkan karena, kandungan yang terdapat pada ekstrak batang pepaya yaitu senyawa aktif saponin. Saponin merupakan senyawa glikosida kompleks yang apabila dihidrolisis akan menghasilkan glikon (gula) dan aglikon (non gula). Gula bersifat higroskopis sehingga dapat menyerap uap air.

Mekanisme pengikatan air oleh gula dipengaruhi oleh osmosis. Osmosis adalah perpindahan molekul air melalui sebuah membran tipis yang terjadi akibat adanya larutan yang berbeda konsentrasinya dari yang pekat ke yang lebih pekat. Semakin banyak jumlah penambahan ekstrak batang pepaya maka semakin rendah kadar air pada sabun tranparan yang dihasilkan.

Widyasanti et al. (2015) yang menggunakan teh putih dengan formulasi 0,5\% (0,5 ml) sebagai bahan aktif pada sabun tranparan dan menghasilkan kadar air sebesar 12,17\%. Banyaknya kadar air dalam sabun akan mengakibatkan sabun lunak dan cepat habis saat digunakan. Secara keseluruhan kadar air yang terkandung dalam sabun transparan tersebut telah memenuhi syarat standar mutu sabun padat (SNI 06-3235-1994) yaitu sebesar $15 \%$. 
Tabel 1. Data pengamatan sabun transparan

\begin{tabular}{|c|c|c|c|c|}
\hline \multirow{2}{*}{ Parameter } & \multicolumn{4}{|c|}{ Perlakuan } \\
\hline & $\mathrm{P} 1$ & $\mathrm{P} 2$ & P3 & $\mathrm{P} 1$ \\
\hline Kadar air (\%) & $13,60^{d}$ & $13,24^{c}$ & $12,82^{\mathrm{b}}$ & $12,19^{a}$ \\
\hline Jumlah asam lemak (\%) & $35,35^{c}$ & $28,55^{b}$ & $27,00^{\mathrm{ab}}$ & $25,58^{a}$ \\
\hline Asam lemak bebas (\%) & $2,36^{c}$ & $2,29 \mathrm{c}$ & $1,73^{\mathrm{b}}$ & $1,53^{a}$ \\
\hline Derajat keasaman $(\mathrm{pH})$ & $9,49 a$ & $10,21^{b}$ & $11,06^{c}$ & $11,82^{\mathrm{d}}$ \\
\hline Stabilitas busa (\%) & $91,86^{b}$ & $91,13^{\mathrm{ab}}$ & $90,99 \mathrm{ab}$ & $89,4^{a}$ \\
\hline $\begin{array}{l}\quad \text { Uji antibakteri } \\
\text { - } \quad \text { S.aureus (mm) } \\
\text { - } \quad \text { E.coli }(\mathrm{mm}) \\
\text { Uji iritasi }\end{array}$ & $\begin{array}{l}6,17^{a} \\
9,19^{a}\end{array}$ & $\begin{array}{c}7,86^{\mathrm{b}} \\
9,62^{\mathrm{ab}}\end{array}$ & $\begin{array}{l}8,57^{\text {bc }} \\
10,33^{c}\end{array}$ & $\begin{array}{c}9 c \\
10,83^{c}\end{array}$ \\
\hline - Eritema & $0,2^{a}$ & $0,1^{\mathrm{a}}$ & $0,05^{a}$ & $0,05^{a}$ \\
\hline - Edema & - & - & - & - \\
\hline
\end{tabular}

\section{Kadar Asam Lemak}

Tabel 1 menunjukkan bahwa jumlah asam lemak berkisar antara 25,58-35,35\%. semakin banyak penambahan ekstrak batang pepaya pada pembuatan sabun transparan maka semakin rendah kadar asam lemak pada sabun transparan. Peningkatan penambahan ekstrak batang pepaya mengakibatkan penurunan asam lemak pada sabun transparan yang dihasilkan Hal ini dikarenakan ekstrak batang pepaya mengandung senyawa aktif alkaloid.

Alkaloid adalah senyawa organik bersifat basa atau alkali (Lenny, 2006). Penurunan asam lemak ini diduga karena kandungan senyawa aktif yaitu alkaloid pada ekstrak batang pepaya. Golongan aktif alkaloid dapat memutuskan ikatan rangkap minyak. Proses pemutusan ikatan rangkap menjadi ikatan tunggal mengakibatkan minyak sawit menjadi jenuh, sehingga jumlah asam lemak pada sabun semakin rendah. Kandungan asam lemak tak jenuh yang terlalu banyak mengakibatkan sabun mudah teroksidasi pada keadaan amfoterik sehingga sabun menjadi tengik. Asam lemak tak jenuh memiliki ikatan rangkap sehingga sabun yang dihasilkan pada keadaan ini akan lebih lembek dan mudah meleleh pada temperatur tinggi.

Hasil penelitian Widyasanti et al. (2016) menunjukkan jumlah asam lemak sabun transparan dengan penambahan ekstrak teh dengan formulasi $0 \mathrm{ml}-1,5 \mathrm{ml}$ juga cukup rendah yaitu berkisar 34,23-38,5\%. Hal yang sama juga terjadi pada penelitian Qisti (2009) yaitu sabun transparan dengan penambahan madu formulasi $0 \mathrm{ml}-7,5 \mathrm{ml}$ memiliki jumlah asam lemak berkisar 20,03-30,64\%. Rendahnya jumlah asam lemak pada sabun transparan disebabkan karena dalam formulasi sabun transparan ditambahkan beberapa bahan tambahan seperti gliserin dan alkohol yang dapat meningkatkan transparansi.

Menurut Qisti (2009), penambahan alkohol yang berfungsi sebagai pembentuk transparansi akan menyebabkan asam lemak larut karena alkohol bersifat non polar sehingga jumlah asam lemak sabun transparan menjadi berkurang. Asam lemak dalam sabun transparan berperan sebagai pengatur konsistensi karena memiliki kemampuan terbatas untuk larut dalam air. Hal ini akan membuat sabun menjadi lebih tahan lama pada kondisi setelah digunakan (Spitz, 1996). Jumlah asam lemak dalam sabun menurut 
Badan Standardisasi Nasional (1994) minimal sebesar 70\%. Hal ini dimaksudkan untuk mengefisienkan proses pembersihan kotoran berupa minyak atau lemak pada saat sabun digunakan.

\section{Asam Lemak Bebas/Alkali Bebas}

Tabel 1 menunjukkan bahwa asam lemak bebas yang dihasilkan berkisar antara $1,53-2,36 \%$. Semakin banyak penambahan ekstrak batang pepaya maka kadar asam lemak bebas semakin rendah. Penambahan ekstrak batang pepaya dapat menurunkan kadar asam lemak bebas pada sabun transparan. Hal ini diduga disebabkan karena kandungan senyawa aktif alkaloid yang terdapat pada ekstrak batang pepaya adalah senyawa organik yang bersifat basa atau alkali (Lenny, 2006).

Kadar asam lemak bebas pada sabun juga dapat dipengaruhi oleh kadar asam lemak bebas pada minyak sawit yang dipergunakan pada pembuatan sabun transparan. Kandungan asam lemak bebas dari minyak sawit yang digunakan yaitu 0,25\%. Asam lemak bebas yang terlalu tinggi dapat mengganggu efektivitas sabun dalam membersihkan kotoran. Menurut Ayu et al. (2010), asam lemak bebas yang tinggi dapat mengurangi daya ikat sabun pada kotoran, minyak, lemak, ataupun keringat. Asam lemak bebas tidak dapat ,mengikat kotoran karena sifatnya polar, berbeda dengan minyak lemak, ataupun kotoran tidak dapat berikatan dengan asam lemak bebas.

Kadar asam lemak bebas maksimal pada sabun transparan padat beradasarkan Badan Standardisasi Nasional (1994) yaitu $<2,5 \%$. Jika kadar asam lemak bebas tinggi maka kecenderungan sabun akan berbau tengik (Padli, 2014). Kadar asam lemak bebas sabun pada penelitian ini yaitu lebih kecil dari 2,5\%, sehingga sabun transparan memenuhi persyaratan mutu sabun mandi.

Besarnya kadar alkali bebas pada penelitian ini tidak dapat dukur, dikarenakan tidak terjadi perubahan warna kembali ketika dititrasi. Hal ini sebanding dengan Nadi, (2017) dimana alkali bebas tidak dapat diukur karena semua alkali telah bereaksi dengan semua asam lemak dari minyak sawit. Menurut Widyanti (2009), kelebihan alkali pada sabun tidak dikehendaki karena dapat menyebabkan panas pada kulit pada saat dipakai, namun kekurangan alkali dapat menyebabkan berlebihnya asam lemak sehingga asam lemak tidak tersabunkan oleh alkali.

\section{Derajat Keasaman (pH)}

Tabel 1 menunjukkan bahwa derajat keasaman $(\mathrm{pH})$ yang diperoleh adalah 9,4911,82. Nilai derajat keasaman pada sabun yang diperoleh cenderung meningkat. Hal ini diduga disebabkan oleh ekstrak batang pepaya mengandung senyawa aktif alkaloid. Menurut Lenny (2006) alkaloid adalah senyawa aktif yang bersifat basa atau alkali.

Menurut Wasiaatmadja (1997), menyatakan bahwa faktor yang mempengaruhi sifat iritasi pada kulit adalah lamanya kontak sabun dengan kulit dan daya absorbsi kulit terhadap sabun. Derajat keasaman $(\mathrm{pH})$ yang diperoleh pada analisis penelitian ini yatu 9,49-11,82. Penelitian yang telah dilakukan oleh Widyasanti (2013) yaitu pH sabun 
transparan dengan penambahan ekstrak teh putih yang dihasilkan berkisar antara 10-11 dengan formulasi $0 \%$ sampai dengan $1,5 \%$. Derajat keasaman $(\mathrm{pH})$ sabun yang dihasilkan menunjukkan hasil yang tidak berbeda jauh hal ini dikarenakan kandungan antara ekstrak yang dimanfaatkan memiliki beberapa kandungan yang sama. Menurut Badan Standardisasi Nasional (1996), pH sabun cair yaitu berkisar antara 8-11, sedangkan pada sabun padat tidak disebutkan. Oleh karena itu pada penelitian ini derajat keasaman $(\mathrm{pH})$ sabun transparan tergolong baik dan dapat diterima.

\section{Stabilitas Busa}

Tabel 1 menunjukkan bahwa stabilitas busa berkisar antara 89,4-91,86 mm. Semakin banyak penambahan ekstrak batang pepaya maka semakin rendah stabilitas busa yang dihasilkan namun, pada setiap perlakuan hanya memberikan sedikit perbandingan saja yaitu dengan selisih $0.72 \mathrm{~mm}-2.46 \mathrm{~mm}$. Hal ini disebabkan karena formulasi sabun transparan yang digunakan yaitu etanol sebagai pelarut.

Etanol $\left(\mathrm{C}_{2} \mathrm{H}_{5} \mathrm{OH}\right)$ merupakan salah satu senyawa organik yang digunakan dalam pembuatan sabun sebagai pelarut karena sifatnya yang mudah larut dalam air dan lemak (Hambali et al., 2005). Etanol berperan sebagai antifoaming agent. Ekstrak batang pepaya mengandung senyawa aktif saponin, saponin menimbulkan busa jika diaduk dalam air karena sifatnya menyerupai sabun namun, karena pelarut menggunakan etanol sehingga memberikan efek untuk menghambat pembentukan busa. Menurut Setyoningrum (2010) menyatakan bahwa antifoaming agent yang berlebihan dapat menurunkan busa yang terbentuk.

Surfaktan adalah molekul yang memiliki gugus hidrofilik dan gugus lipofilik sehingga dapat mempersatukan campuran yang terdiri dari minyak dan air. Surfaktan dapat menstabilkan busa dengan cara menurunkan tegangan permukaan antara fasa minyak dengan fasa air. Penelitian ini penggunaan surfaktan dietanolamida dapat mempertahankan busa selama waktu uji. Hal ini sesuai dengan Febriyenti et.al. (2014) yang menyatakan bahwa penggunan surfaktan dietanolamin dalam membuat sabun transparan mampu mempertahankan busa dalam waktu lima menit. Bahan pembuatan sabun yang juga berperan dalam menstabilkan busa yaitu asam stearat. Menurut Wade dan Weller (1994) bahwa asam stearat dapat digunakan sebagai pengeras sabun dan penstabil busa.

\section{Uji Aktivitas Antibakteri}

Tabel 1 menunjukkan bahwa Sabun transparan dengan penambahan ekstrak batang pepaya pada setiap perlakuan baik terhadap bakteri S.aureus dan E.coli memiliki kategori sedang dengan daya hambat berkisar 6,17 $\mathrm{mm}-10,83 \mathrm{~mm}$. Menurut Davis dan Stout (1971) kategori daya hambatan dengan nilai $20 \mathrm{~mm}$ atau lebih termasuk kategori sangat kuat, nilai 5- $10 \mathrm{~mm}$ kategori sedang, dan daerah hambatan dengan nilai $5 \mathrm{~mm}$ atau kurang termasuk pada kategori lemah. Ekstrak batang pepaya yang ditambahkan pada 
pembuatan sabun padat transparan berada pada kategori sedang baik terhadap S.aureus maupun E.coli.

Tabel 1 menunjukkan bahwa semakin banyak penambahan ekstrak batang pepaya pada pembuatan sabun transparan maka semakin meningkat luas zona bening yang terbentuk yang menunjukkan bahwa aktivitas antibakteri semakin baik terhadap bakteri S.aureus dan E.coli. Kemampuan menghambat terhadap kedua bakteri uji ini disebabkan adanya senyawa antibakteri pada ekstrak batang pepaya. Menurut Oladimedji et al., (1999) senyawa aktif ekstrak batang pepaya yang berfungsi sebagai agen antibakteri yaitu senyawa saponin dan antrakuonin. Mekanisme kerja saponin sebagai agen antibakteri adalah menurunkan tegangan tegangan permukaan sehingga mengakibatkan naiknya permeabilitas atau kebocoran sel dan mengakibatkan senyawa intraseluler akan keluar (Ngajow et al. 2013). Senyawa ini berdifusi melalui membran luar dan dinding sel yang rentan, lalu mengikat membran sitoplasma, mengganggu dan mengurangi kestabilannya sehingga menyebabkan sitoplasma bocor dan keluar dari sel.

Efek menghambat pertumbuhan bakteri berhubungan dengan senyawa fenol yang terkandung di dalamnya. Senyawa fenol yang terdapat dalam ekstrak batang pepaya salah satunya adalah antrakuinon. Menurut Oladimedji et al., (1999) mekanisme kerja senyawa aktif antrakuinon sebagai antibakteri dengan cara menghambat transfer elektron pada rantai pernafasan mitokondria, mengganggu atau merusak komponen dinding sel yakni peptidoglikan, menonaktifkan enzim-enzim esensial, perampasan mineral bakteri dan mengganggu kerja membran sitoplasma yang akan menyebabkan terganggunya proses metabolisme bakteri yang akhirnya mengakibatkan kematian bakteri. Luas zona bening terhadap bakteri E.coli lebih besar dibandingkan dengan S.aureus hal ini disebabkan karena bakteri E.coli lebih sensitif terhadap antrakuinon dibandingkan saponin.

\section{Uji Iritasi}

Tabel 1 menunjukkan penambahan ekstrak batang pepaya memberikan perbedaan tidak nyata terhadap iritasi yang ditimbulkan. Adapun penyebabnya adalah ekstrak batang pepaya tidak mengandung komponen yang dapat menyebabkan iritasi pada kulit. Menurut Julianto (2016), bahan atau sampel yang mengandung senyawa aldehid (misalnya sitronellal, sitral) dan fenolik (misalnya asam salsilat dan eugenol) dapat menyebabkan iritasi pada kulit.

Penyebab iritasi pada beberapa panelis disebabkan karena nilai $\mathrm{pH}$ sabun transparan yang dihasilkan relatif tinggi dibandingkan dengan $\mathrm{pH}$ kulit manusia. Nilai $\mathrm{pH}$ yang relatif tinggi dapat menyebabkan kulit dehidrasi dan iritasi pada kulit. Pada penelitian ini $\mathrm{pH}$ sabun sudah memenuhi standar yang ditetapkan Badan Standardisasi Nasional (1996), akan tetapi ritasi dapat terjadi oleh karena kesensitifan kulit panelis terhadap zat yang digunakan. Menurut Hadia dalam Nadi (2017), menyatakan bahwa 
sensitivitas kulit seseorang dapat berbeda-beda, tergantung pada kesehatan kulit, hormon dan genetiknya.

Penelitian yang telah dilaksanakan oleh Rustiani (2013) menunjukkan bahwa sabun transparan dengan penambahan minyak atsiri akar wangi tidak menimbulkan efek iritasi terhadap kulit panelis, tetapi sabun transparan hasil penelitian ini menimbulkan sedikit eritema, meskipun demikian sabun transparan ini masih dikatakan aman. Berdasarkan penelitian Priyani dan Lukmayani (2010) apabila rata-rata skor yang diperoleh anatara 0,04-0,99 (hampir tidak mengiritasi) menunjukkan bahwa produk sabun transparan cukup aman untuk digunakan.Selanjutnya hasil dari uji lanjut dari setiap perlakuan pada berbagai pengataman, direkapitulasi dalam Tabel 2 untuk penentuan perlakuan terpilih pada penelitian. Standar Nasional Indonesia menjadi dasar pertimbangan dalam pengambilan perlakuan terpilih, selanjutnya dilihat hasil uji lanjut antar perlakuan untuk setiap pengamatan.

Tabel 2. Rekapitulasi Hasil Perlakuan Terpilih

\begin{tabular}{|c|c|c|c|c|c|}
\hline \multirow{2}{*}{ Parameter uji } & \multirow{2}{*}{ SNI } & \multicolumn{4}{|c|}{ Perlakuan } \\
\hline & & P1 & P2 & P3 & P4 \\
\hline Kadar air (\%) & Maks $15^{*}$ & $13,60^{\mathrm{d}}$ & $13,24^{c}$ & $12,82^{\mathrm{b}}$ & $12,19^{a}$ \\
\hline Jumlah asam lemak (\%) & $>70^{*}$ & $35,35^{\mathrm{c}}$ & $28,55^{\mathrm{b}}$ & $27,00^{\mathrm{ab}}$ & $25,58^{a}$ \\
\hline Asam lemak bebas (\%) & $<2,5$ * & $2,36^{c}$ & $2,29^{c}$ & $1,73^{\mathrm{b}}$ & $1,53^{\mathrm{a}}$ \\
\hline $\mathrm{pH}$ & $8-11^{* *}$ & $9,49^{a}$ & $10,21^{\mathrm{b}}$ & $11,06^{c}$ & $11,82^{\mathrm{d}}$ \\
\hline Stabilitas busa (\%) & - & $91,86^{\mathrm{b}}$ & $91,13^{a b}$ & 90,99 ab & $89,4^{a}$ \\
\hline Uji antibakteri & & & & & \\
\hline - S.aureus (mm) & & $6,17^{\mathrm{a}}$ & $7,86^{\mathrm{b}}$ & $8,57^{\mathrm{bc}}$ & $9^{c}$ \\
\hline 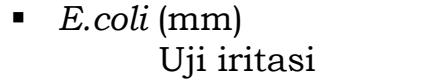 & & $9,19^{a}$ & $9,62^{\mathrm{ab}}$ & $10,33^{c}$ & $10,83^{c}$ \\
\hline - Eritema & & $0,2^{\mathrm{a}}$ & $0,1^{\mathrm{a}}$ & $0,05^{a}$ & $0,05^{a}$ \\
\hline - Edema & & - & - & - & - \\
\hline
\end{tabular}

Bedasarkan nilai kadar air, semua perlakuan telah memenuhi syarat mutu sabun padat. Sabun yang berkualitas baik adalah sabun yang memiliki kadar air yang rendah karena memberikan daya simpan yang baik dan tidak mudah menyusut saat digunakan. Kadar asam lemak belum memenuhi standar mutu adanya penambahan bahan pelembab dan pembentuk transparansi. Kadar asam lemak bebas semua perlakuan memenuhi standar mutu. pH sabun transparan pada semua perlakuan telah memenuhi syarat mutu yang ditetapkan oleh BSN (1996) yaitu sebesar 8-11. Sabun transparan hasil penelitian memiliki stabilitas busa di atas $88 \%$. Sabun antibakteri yang baik adalah sabun yang kemampuan hambatnya terhadap bakteri paling besar.

Berdasarkan rekapitulasi hasil penelitian, sabun transparan dengan perlakuan terbaik adalah P3 yaitu memiliki kadar air 12,82\%, kadar asam lemak 27,00, asam lemak bebas $1,73 \%, \mathrm{pH}, 11,06$, stabilitas busa 90,9\%, aktivitas antibakteri terhadap S.aureus $8,57 \mathrm{~mm}$ dan terhadap E.coli 10,33 mm, uji iritasi eritema 0,05 (hampir tidak tampak). 


\section{KESIMPULAN}

Penambahan ekstrak batang pepaya berpengaruh nyata terhadap kadar air, kadar asam lemak, asam lemak bebas, $\mathrm{pH}$, stabilitas busa, uji antibakteri dan uji iritasi. Perlakuan terpilih dalam penelitian ini adalah perlakuan P3 (penambahan ekstrak batang pepaya $20 \mathrm{ml}$ ) dengan kadar air 12,82\%, kadar asam lemak 27,00, asam lemak bebas 1,73\%, pH 11,06, stabilitas busa 90,99\%, aktivitas antibakteri terhadap S.aureus 8,57 mm dan terhadap E.coli 10,33 mm, uji iritasi eritema 0,05 (hampir tidak tampak).

\section{DAFTAR PUSTAKA}

Ayu, D. F., A. Ali., dan R. Sulaiman. 2010. Evaluasi mutu sabun padat dari minyak goreng bekas makanan jajanan di kecamatan tampan kota pekanbaru dengan penambahan natrium hidroksida dan lama waktu penyabunan. Prosiding Seminar Nasional Lingkungan Hidup. Pekanbaru.

Badan Standardisasi Nasional. 1994. Standar Mutu Sabun Mandi Padat SNI 06-3532.1994. Jakarta.

Badan Standarisasi Nasional. 1996. Standar Mutu Sabun Cair SNI 06-4085. Jakarta.

Febriyenti., L. I. Sari., dan R. Nofita. 2014. Formulasi sabun transparan minyak ylangylang dan uji efektivitas terhadap bakteri penyebab jerawat. Jurnal Sains Farmasi dan Klinis. 1(1), 61-71.

Hambali, E., T. K. Bunasor., A. Suryani., dan G. A. Kusumah. 2004. Aplikasi dietanolamida dari asam laurat minyak inti sawit pada pembuatan sabun transparan. Jurnal Teknologi Industri Pertanian. 15(2), 46-53.

Julianto, T. S. 2016. Minyak Atsiri Bunga Indonesia. Penerbit Deepublish. Yogyakarta.

Lenny, S. 2006. Senyawa Flavonoid, Fenilpropanoida dan Alkaloida. Fakultas MIPA. USU, Medan.

Nadi, B. S., 2017. Pemanfaatan minyak atsiri rimpang jeringau (Acorus calamus L.) Sebagai antibakteri sabun transparan. Skripsi. Universitas Riau. Pekanbaru.

Ngajow, M., A. Jemmy, Kamu.V. S. 2013. Pengaruh antibakteri ekstrak kulit batang matoa (Pometia pinnata) terhadap bakteri S.aureus secara in vitro. Jurnal MIPA UNSRAT Online. Volume 2 (2) 128-132.

Oladimedji , O. H., R Nia, K Ndukwe, dan M Attih. 2007. In Vitro Biological Activity Of Seed Carica papaya. Journal of Medical Plant. 1 (3), 92-99.

Priyani, S. E., dan Y. Lukamanyani. 2010. Pembuatan sabun transparan be. han dasar minyak jelantah beserta hasil uji iritasinya pada kelinci. Prosiding Seminar Nasional 2010. Edisi Eksakta. Hal 31-44.

Qisti, R. 2009. Sifat kimia sabun transparan dengan penambahan madu pada konsentrasi yang berbeda. Skripsi. Institut Pertanian Bogor. Bogor.

Rahman, S., Imran, M., Muhammad, N., Hassan, N., Chisthi, A. K., Khan, A. F. 2011. Antibacterial screening of leaves and stem of Carica papaya. Journal Of Medicinal Plants Research. 5 (20), 5167-5171.

Rustiani, E. 2013. Pembuatan sabun transparan aromaterapi minyak atsiri akar wangi (Chrysopogon zizanioides L.). Skripsi. Universitas Pakuan. Bogor.

Setiawan, W. 2009. Aktivitas antibakteri ekstrak etanol batang pepaya (carica papaya L.) terhadap Staphylococcus aureus dan Escherichia coli multiresisten antibiotik. Skripsi. Universitas Surakarta. Surakarta.

Setyaningsih, D., A. Anton, dan P. S. Maya. 2010. Analisis Sensori untuk Industri Pangan dan Agro. IPB Press: Bogor. 
Siska, J. 2009. Isolasi dan uji aktifitas antimikroba ekstrak metanol bunga tumbuhan dahlia (Dahlia variabilis). Skripsi. Universitas Riau. Pekanbaru.

Spitz, L. 1996. Soap and Detergen a Theorical and Practical Review. AOCS Press. Champaign-Illionis.

Sudarmadji, S., B. Haryono., dan Suhardi. 1997. Prosedur untuk Analisa Bahan Makanan dan Pertanian. Yogyakarta: Liberty.

Trifena. 2012. Analisis uji invitro dan invivo ekstrak kombinasi kulit manggis (Garcinia mangostona 1.) dan pegangan (Centella asiatica 1.) sebagai krim antioksidan. Tesis. Fakultas Matematika dan Ilmu Pengetahuan Alam Universitas Indonesia. Depok.

Wade, A dan Weller, P. J. 1994. Handbook of Pharmaceutical Recipients Secoend Edition. American Pharmaceutical Association. Washington.

Wasitaatmadja, S.M. 1997. Penuntun Ilmu Kosmetik dan Medik. Jakarta: UI Press.

Widyasanti, A, Farddani, C.L dan Rohdiana, D. 2016. MAKING OF Transparent Solid Soap Using Palm Oil Based with Addition White Tea Extracts (Camellia sinensis). Jurnal Teknik Pertanian Lampung. 3, 125-136.

Wulandari, H. 2013. Efek antibakteri ekstrak etanol batang pepaya (Carica papaya L.) terhadap pertumbuhan bakteri pada plak gigi. Skripsi. Universitas Sebelas Maret. Surakarta. 